SECTION 31. Economic research, finance, innovation.

Kovalenko Gennady Vasilyevich Associate Professor, Ph.D., The St.Petersburg State Polytechnical University, Russia 7525268@gmail.com

\title{
ABOUT THE FACTORS OF DEVELOPMENT OF WOOD GASIFICATION AS A TECHNOLOGY OF "TIME OF TROUBLES"
}

\begin{abstract}
The level of demand for the gasification technology in society depending on the historical and socio-economic reasons is put under consideration. The inconsistency of interests in the development of the gasification technology as an integral part of bioenergetics of socio-economic groups in Russia and abroad is analyzed. The reasons for the commercialization success of the gasification technology of scientists and entrepreneurs from the United States are stated.
\end{abstract}

Key words: gasification, bio-energy, small energy, commercialization, technology, innovation.

УДК 338.001.36:66.092-977

\section{О ФАКТОРАХ РАЗВИТИЯ ГАЗИФИКАЦИИ ДРЕВЕСИНЫ КАК ТЕХНОЛОГИИ «СМУТНОГО ВРЕМЕНИ»}

\begin{abstract}
Аннотация: Дискутируется степень востребованности технологии газификаџии в жизни общества в зависимости от исторических и сочилальноэкономических причин. Анализируется несогласованность интересов сочииальноэкономических групп в России и за рубежом в развитии технологии газификаџии как составной части биоэнергетики. Показываются причины успешности коммерциализации технологии газификации учеными и предпринимателями из США.
\end{abstract}

Ключевые слова: газификачия, биоэнергетика, малая энергетика, коммерциализачия, технология, инноващии.

В современных условиях ценовой турбулентности на невозобновляемые энергетические ресурсы и нарастания ожиданий очередного финансового кризиса естественным образом актуализируется потребность в альтернативных возобновляемых источниках энергии. Одним из таких источников является древесина, энергию из которой можно извлекать используя технологию газификации.

В большей части отечественных публикаций о газификации древесины, как правило, делается заключение о недооценке ее роли в энергетике, необходимости повышения этой роли и перспективности газификации как составного элемента биоэнергетики в условиях нашей страны с ее значительными ресурсами древесины $[1,2,3,4,5]$. Однако среди многочисленных публикаций по газогенераторной тематике практически нет изданий по экономике газогенерации, написанных так же обстоятельно, что и работы по техническим, технологическим, историческим вопросам. Это не случайно, так как в значимых масштабах к технологии газификации обращаются только в кризисной ситуации - в период войн, катастроф, финансово-сырьевой нестабильности. Газификация древесины - это технология «смутного времени», когда приоритетом становится не эффективность варианта решения, обеспечивающего выживаемость, а само физическое выживание отдельного человека, его семьи и бизнеса. 
Технология газификации во всем мире рассматривается как неотъемлемая часть биоэнергетики. В 2009 году автором в статье об экономических интересах в развитии биоэнергетики [6] были сформулированы предположения о социально-экономических группах, которым выгодно развитие биоэнергетики в России - это, прежде всего местные власти (точнее говоря, население), а также малый и средний бизнес. Практика подтвердила эти предположения [7].

С формальной точки зрения, в России есть все предпосылки для того, чтобы технология газификации древесины, как составная часть биоэнергетики, заняла достойное место в обеспечении энергобезопасности страны. Как было показано в [8], в России есть социально-экономические группы, заинтересованные в развитии технологии газификации древесины. Малый и средний бизнес по своей природе заинтересован в развитии альтернативных источников энергии. Находясь в условиях экономической, технической, технологической и ресурсной недоступности [9] стационарной внешней энергоинфраструктуры и наличия экологических ограничений для осуществления своей производственной деятельности, такой бизнес потенциально готов предъявлять спрос на малые энергетические установки, работающие на принципах газификации. Население будет приветствовать любую инициативу, которая способствует повышению как физической, так и ценовой доступности, и бесперебойности энергоснабжения, одновременно выступает фактором, препятствующим росту цен на потребляемую энергию. Безусловно, заинтересованы в развитии технологии газификации отечественные ученые и энтузиасты-инноваторы.

Однако, все указанные выше мотивации применительно к условиям России вряд ли могут быть реализованы.

Таблица 1

Факторы развития газификации

\begin{tabular}{|l|c|c|c|}
\hline \multicolumn{1}{|c|}{ Показатель } & РФ & $\begin{array}{c}\text { США и } \\
\text { Канада }\end{array}$ & $\begin{array}{c}\text { Страны } \\
\text { Евросоюза }\end{array}$ \\
\hline $\begin{array}{l}\text { Кратность запасов природного газа на конец } \\
2012 \text { года, лет [10] }\end{array}$ & 56 & около 13 & примерно 12 \\
\hline $\begin{array}{l}\text { Доля малого и среднего } \\
\text { предпринимательства в ВВП, \% [11] }\end{array}$ & $10-11$ & $50-52$ & $63-67$ \\
\hline
\end{tabular}

Во-первых, как видно из табл. 1, в аспекте ограниченности запасов невозобновляемого углеводородного сырья в России отсутствуют «ресурсные» причины для значимого интереса (сравнительно с США, Канадой и Евросоюзом), включая интерес государства, к технологии газификации древесины.

Во-вторых, в социально-экономической жизни России мала роль малого и среднего бизнеса, который является залогом динамичного и устойчивого развития экономики. Научные организации не имеют стимула и финансовых возможностей для проведения масштабных НИОКР, необходимых для подтягивания технологии «смутного» времени к современным технико-экономическим реалиям и дальнейшего ее развития. Ведь до сих пор не решены проблемы с очисткой и охлаждением генераторного газа, утилизацией побочных продуктов и отходов процесса газификации, подбора теплоизолирующих материалов для активной зоны термохимической реакции, не говоря уже о системах управления «газификатор-электрогенератор».

Результатом такого положения дел в России является наличие гордости у отечественной науки за свои достижения в области газификации древесины в 60-х годах. Рыночные же воплощения этих достижений на отечественном рынке отсутствуют [12]. 
Обратная ситуация с развитием технологии газификации складывается в США и, что характерно, как раз в области малой энергетики. Технология газификации древесины (даже шире - воспроизводимых углеводородов) востребована учеными из исследовательских организаций и образовательных учреждений, малым и средним бизнесом в лесной, сельскохозяйственной и промышленной областях деятельности, и частными домовладельцами, вплоть до местных муниципалитетов. Показательный пример тому - open-source проект The GEK Project компании ALL Power Labs, в рамках которого с 2008 года, опираясь на результаты экспериментальных исследований сети из 50-ти университетов и научных центров, к концу 2013 года было установлено свыше 500 компактных газогенераторных энергоустановок в более чем 50 стран мира. В конце 2013 года ALL Power Labs вывела на рынок пятую версию газификатора древесины GEK Gasifier и разработанные на его основе электростанции Power Pallet класса DIY Power @ Play от самой простой до полностью автоматической мощностью 10 и 20 кВт. Эти электростанции способны работать в круглосуточном режиме, с возможностью загрузки сырьем и проведения ряда операций технического обслуживания без остановки газификатора. Удельные инвестиции покупателей таких электростанций в расчете на 1 кВт мощности находятся в диапазоне от одного до двух долларов США, что оказывается коммерчески привлекательным для потребителей электроэнергии из приведенного выше сегмента рынка, обеспечивает коммерциализацию результатов НИОКР в области газификации древесины и, соответственно, дальнейшее развитие этой технологии получения энергии, несмотря на видимую «смутность».

Таким образом, несмотря на то, что газификация древесины является технологией «смутного времени» с соответствующей «затратной» экономикой, она имеет коммерческий успех в странах, неуклонно диверсифицирующих энергетику во всех секторах экономики и социальной жизни. Причина успеха - совпадение интересов различных социально-экономических групп в этих странах в развитии экономики, базирующейся на возобновляемых ресурсах, в том числе энергетических. Этого пока не наблюдается в России.

\section{Литература}

1. Копытов, В.В. Газификация конденсированных топлив. - М.: Инфра-Инженерия, 2012. $-504 \mathrm{c}$.

2. Садртдинов, А. Р. Совершенствование техники и технологии процесса газификации отходов деревообработки: дис. ... канд. техн. наук: 05.21.05., 05.21.03. / А.Р. Садртдинов. - Казань, 2011. - 177 с.

3. Кузнецов, В. А. Исследование воздушно-плазменной газификации биомассы по обращенной схеме: дис. ... канд. техн. наук : 01.04.13. / В. А. Кузнецов. - СанктПетербург, 2011. - 132 с.

4. Передерий, С. Перспективы использования биотоплива из древесного сырья// Леспроминформ. 2013. N. 8 (98). С. 170-177.

5. Кашкаров, А.П. Современные био -, бензо -, дизель-генераторы и другие полезные конструкции. - М.: ДМК Пресс, 2011. - 136 с.

6. Коваленко, Г. В. Об интересах в развитии биоэнергетики // Леспроминформ. 2009. N. 8 (66). C. $20-22$.

7. Передерий, С. Зачем пеллеты российской «коммуналке» // Леспроминформ. 2013. N. 2 (92). C. 164-168.

8. Коваленко, Г.В.; Ким, В.Г.; Коваленко, М.В. Ренессанс и перспективы газогенерации в России: о социально-экономических интересах в развитии «технологии смутного времени» // Леспроминформ. 2013. N. 2 (92). С. 24-26. 
9. Коновалова, Л. П. Электроснабжение децентрализованных потребителей Томской области с использованием возобновляемых источников энергии: автореф. дис. ... канд. техн. наук: 05.09.03. / Л.П. Коновалова. - Томск, 2007. - 26 с.

10. Statistical review of world energy 2013. Workbook, June 2013. bp.com/statisticalreview - Дата обращения: 12.12.2013.

11. Плисов, А. Сравнение отечественного и международного малого бизнеса (на примере Республики Коми) / Центр по устойчивому развитию. http://www.agiks.ru/data/csd/files/sme_compare_rus.pdf - Дата обращения: 12.12.2013.

12. Коваленко, Г.В. Коммерциализация научно-технического потенциала газогенерации за рубежом и ее перспективы в России. // Леспроминформ. 2013. N. 3 (93). C. 168-170. 